\title{
Excellent bonding behaviour of novel surface-tailored fibre composite rods with cementitious matrix
}

\author{
FERNANDO CUNHA $^{1}$, SOHEL RANA ${ }^{1, *}$, RAUL FANGUEIRO ${ }^{1,2}$ and GRAÇA VASCONCELOS ${ }^{2}$ \\ ${ }^{1}$ Fibrous Materials Research Group (FMRG), School of Engineering, University of Minho, Guimarães 4800-058, \\ Portugal \\ ${ }^{2}$ Department of Civil Engineering, University of Minho, Guimarães 4800-058, Portugal
}

MS received 21 March 2013; revised 10 October 2013

\begin{abstract}
Novel composite rods were produced by a special braiding technique that involves braiding of polyester yarns around a core of resin-impregnated carbon fibres and subsequent curing. The surface roughness of these braided rods was tailored by replacing one or two simple yarns in the outer-braided layer with braided yarns (produced from 8 simple yarns) and adjusting the take-up velocity. Pull-out tests were carried out to characterize the bond behaviour of these composite rods with cementitious matrix. It was observed that the rod produced with two braided yarns in the outer cover and highest take-up speed was ruptured completely before pull-out, leading to full utilization of its tensile strength, and exhibited $134 \%$ higher pull-out force as compared to the rods produced using only simple braiding yarns.
\end{abstract}

Keywords. Composite rods; surface tailoring; cementitious matrix; pull-out test; bonding characteristics.

\section{Introduction}

Fibre-reinforced polymers (FRPs) are attracting immense attention its use in for strengthening of concrete structures because of its several benefits such as light weight, high specific strength, less corrosion problem, design flexibility (Hollaway 2010). The effectiveness of concrete reinforcement by FRPs depends strongly on the bond behaviour between FRPs and concrete substrate and it is highly desirable to achieve full strength of FRPs before debonding from the concrete (Sayed-Ahmed et al 2009; Iovinella et al 2013). According to recent studies, the bonding strength of FRPs with concrete depends on various parameters such as FRP's embedded length, diameter, surface roughness and strength of concrete and attempts have been made to understand and control these parameters to improve the bonding characteristics (Baena et al 2009; Iovinella et al 2013; Kalupahana et al 2013; Sharakya et al 2013). As surface roughness is a critical parameter influencing the bond behaviour, efforts have been directed towards improving the roughness of concrete surface through various surface preparation methods such as brushing, grinding, scarifying, bush-hammering and steel shot blasting with associated advantages and disadvantages in terms of desired surface roughness, cost and processing time (Iovinella et al 2013). In the present paper, an alternative method has been reported to enhance the bonding characteristics between FRPs and concrete

*Author for correspondence (soheliitd2005@gmail.com) substrate through a novel surface tailoring technique. Composite rods have been produced using braiding technique and the surface geometry of these rods has been tailored through adjustment of braiding process parameters (take-up speed) and changing the type of braiding yarns (simple or braided). The bonding behaviour of these composite rods with cement matrix has been characterized using pull-out tests and the results have been discussed.

\section{Experimental}

Surface-tailored FRP rods were produced using a low-cost, flexible and single-step braiding technique (patented by authors) in which impregnation of core fibres with resin, braiding and consolidation of the braided structures were performed simultaneously (Fangueiro et al 2007). The resulting braided structures were subsequently cured to produce composite rods. Four types of rods were produced. In the basic type, 16 polyester yarns (linear density of 11 tex) were braided around 2 carbon rovings (1600 tex linear density) at a take-up velocity of $0.54 \mathrm{~m} / \mathrm{min}$ to produce composite rods with a relatively smooth surface. The other three types of rods were surface tailored and produced by replacing one or two polyester yarns (among 16 yarns) with polyester braids, each produced with 8 polyester yarns and by varying the take-up velocity. The details of these samples and their braiding angles are listed in table 1 . The schematic representation of the structure of the produced rods is shown in figure 1 . The change in the braided structure and the take-up speed resulted 
Table 1. Details of the produced composite rods.

\begin{tabular}{|c|c|c|c|c|}
\hline Sample code & Core structure & Braided structure & Speed (m/min) & Braiding angle $\left({ }^{\circ}\right)$ \\
\hline SIMPLE & 2 carbon yarns & 16 polyester yarns & $0 \cdot 54$ & 35 \\
\hline 1B_LS & 2 carbon yarns & $\begin{array}{l}15 \text { polyester yarns and } 1 \text { braided structure made of } \\
8 \text { polyester yarns }\end{array}$ & $0 \cdot 54$ & 33 \\
\hline 2B_LS & 2 carbon yarns & $\begin{array}{l}14 \text { polyester yarns and } 2 \text { braided structures made of } \\
8 \text { polyester yarns }\end{array}$ & $0 \cdot 54$ & 49 \\
\hline 2B_HS & 2 carbon yarns & $\begin{array}{l}14 \text { polyester yarns and } 2 \text { braided structures made of } \\
8 \text { polyester yarns }\end{array}$ & 1.07 & 15 \\
\hline
\end{tabular}

(a)

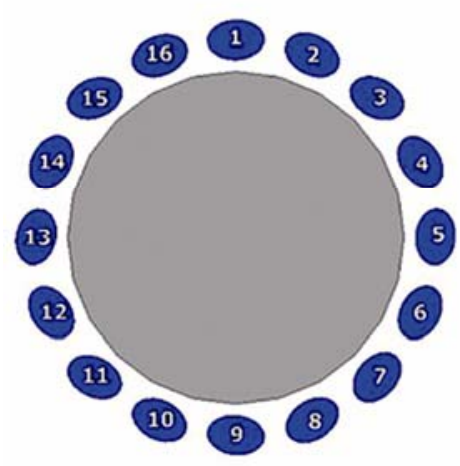

(b)

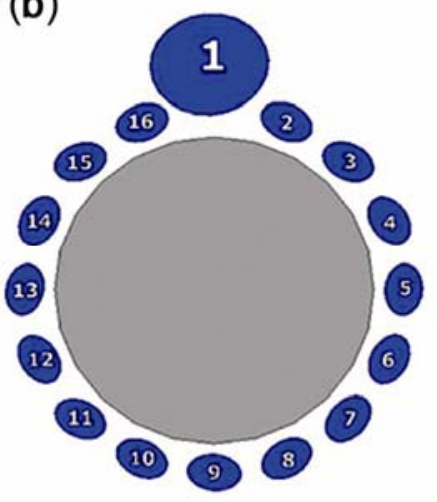

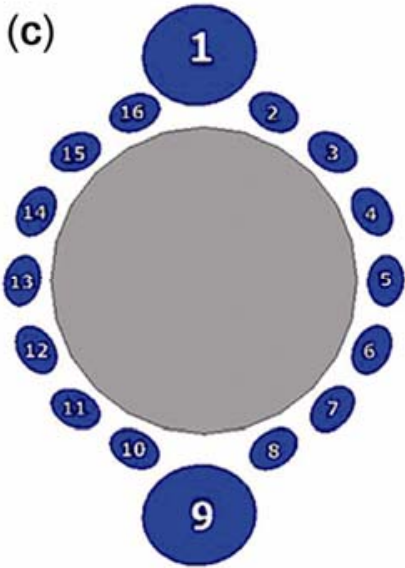

Figure 1. Schematic representation of structure of various composite rods: (a) SIMPLE, (b) 1B_LS and (c) 2B_LS or 2B_HS.

in significant difference in the surface geometry of the rods, as illustrated in figure 2 . It was noticed that the height of the surface ribs $(h)$ was approximately the same $(\sim 0.5 \mathrm{~mm})$ for all the surface-tailored rods. However, the distance between the surface ribs $(D)$ varied significantly from one rod to another.

\section{Characterization of bond behaviour}

Mortar samples for pull-out testing were prepared using cylindrical moulds (10 cm long with $5 \mathrm{~cm}$ diameter) according to NP EN 196-1 2006 standard, keeping the braided rods in the centre of the moulds and allowing to set for 28 days before testing. The samples for pull-out test and the test set up are shown in figure 3.

The tests were performed using a universal testing machine (Lloyd LR50K) at a speed of $0.5 \mathrm{~mm} / \mathrm{min}$ with a gap of $30 \mathrm{~mm}$ between the jaws and pre-tension of $10 \mathrm{~N}$. The pull-out of rods from the cement mortar is illustrated in figure 3(c).

\section{Results and discussion}

\subsection{Pull-out test results}

The results of pull-out test are provided in figure 4 . The rods show an initial linear region, where they elongate
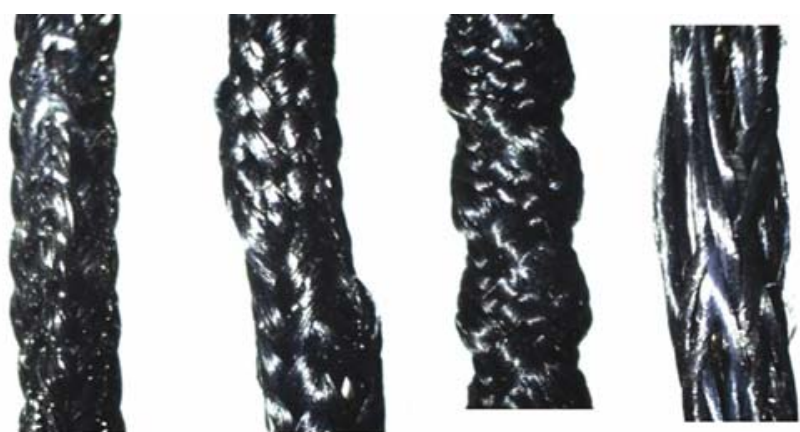

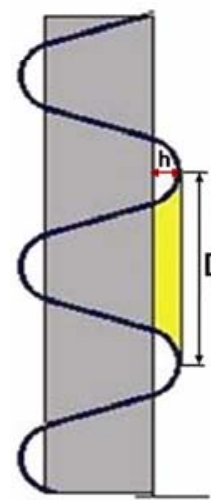

(a)

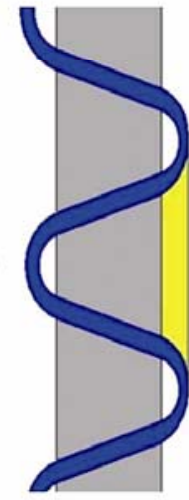

(b)

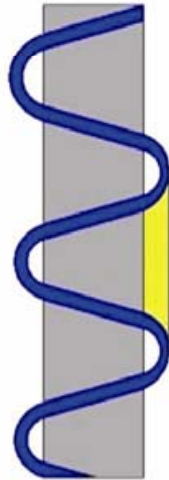

(c)

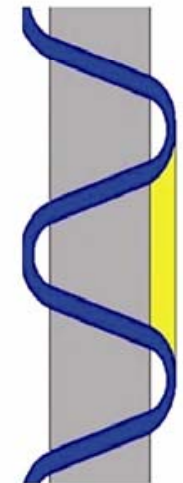

(d)
Figure 2. Surface geometry of produced composite rods: (a) SIMPLE, (b) 1B_LS, (c) 2B_LS and (d) 2B_HS 
Table 2. Comparison of maximum pull-out force of various composite rods.

\begin{tabular}{lccc}
\hline Samples & $\begin{array}{c}\text { Distance between } \\
\text { the ribs, } D(\mathrm{~mm})\end{array}$ & $\begin{array}{c}\text { Maximum } \\
\text { pull-out force }(\mathrm{N})\end{array}$ & \% increase \\
\hline SIMPLE & - & $902 \cdot 5$ & - \\
1B_LS & $14 \cdot 4$ & $1186 \cdot 4$ & 31 \\
2B_LS & $7 \cdot 45$ & $645 \cdot 2$ & -28 \\
2B_HS & $15 \cdot 4$ & $2112 \cdot 6$ & 134 \\
\hline
\end{tabular}
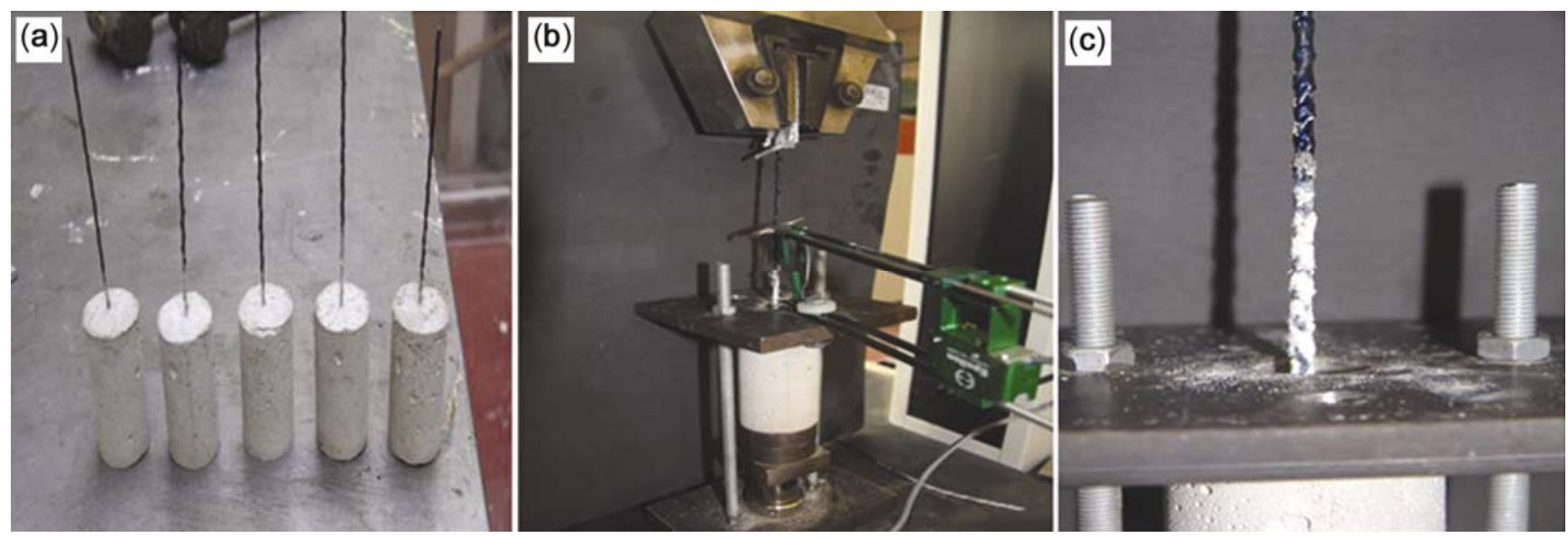

Figure 3. Samples for (a) pull-out test, (b) test setup and (c) pulled-out surface.

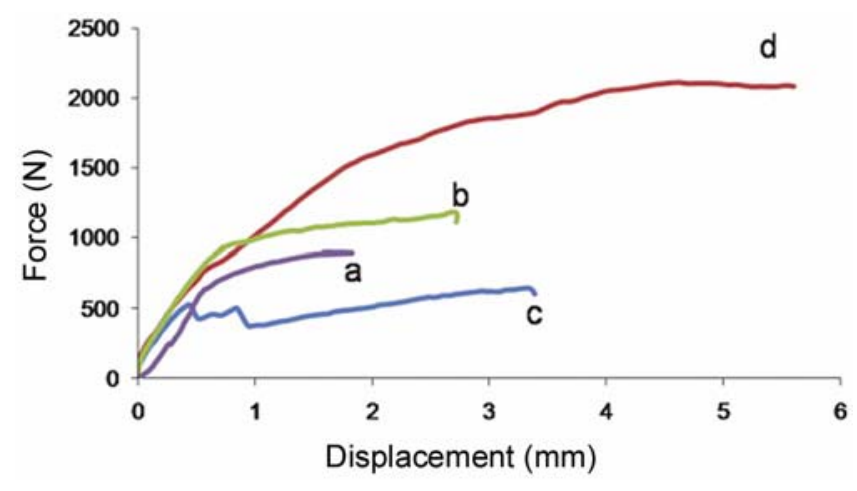

Figure 4. Load-displacement curves during pull-out testing of various composite rods: (a) SIMPLE, (b) 1B_LS, (c) 2B_LS and (d) 2B_HS.

elastically with no slip between the rods and the mortar. After a certain load, slip starts due to the onset of debonding and the rods continue to debond at a almost constant applied force (except 2B_HS) until they are pulled out completely from the mortar. However, in case of 2B_HS, the pull-out force keeps on increasing till the complete rupture of the rod. Therefore, it can be claimed that the bonding between 2B_HS type rod and the mortar was excellent and this resulted in full utilization of its tensile strength. It can be noted here that an increase in the rib distance or $D$ leads to an increase in the pull-out force for the surface-tailored rods, as can be seen from table 2. This was probably attributed to the fact that an increase in $D$ results in higher contact area (shown in yellow in figure 2) of the rods with the mortar and, therefore, results in better adhesion.

\subsection{Pull-out surface morphology}

The pull-out surface of composite rods (i.e. the outer surface that was bonded to the cementitious matrix in the mortar samples and pulled out from the cementitious matrix during the pull-out tests), as observed by scanning electron microscopy (SEM), revealed the presence of a thin layer of concrete that was sheared during the debonding process and attached to the surface of the rods. Moreover, the fibres in the braided layer of the rods were also broken during debonding. However, the surface of the simple braided rods was much less damaged, with breakage of only a few fibres during pull-out, as shown in figure 5(a). This fact is indicative of poor adhesion of these rods with the mortar substrate.

On the contrary, the surface of 2B_HS showed considerable damage of the surface with breakage of many fibres (figure 5d) due to very good adhesion with the mortar and this resulted in the tensile rupture of this rod before complete pull-out. The surface of 1B_LS was also severely damaged (figure 5b), indicating good adhesion, and therefore, resulted in $31 \%$ higher pull-out force than that of the simple rods. However, the surface damage in 

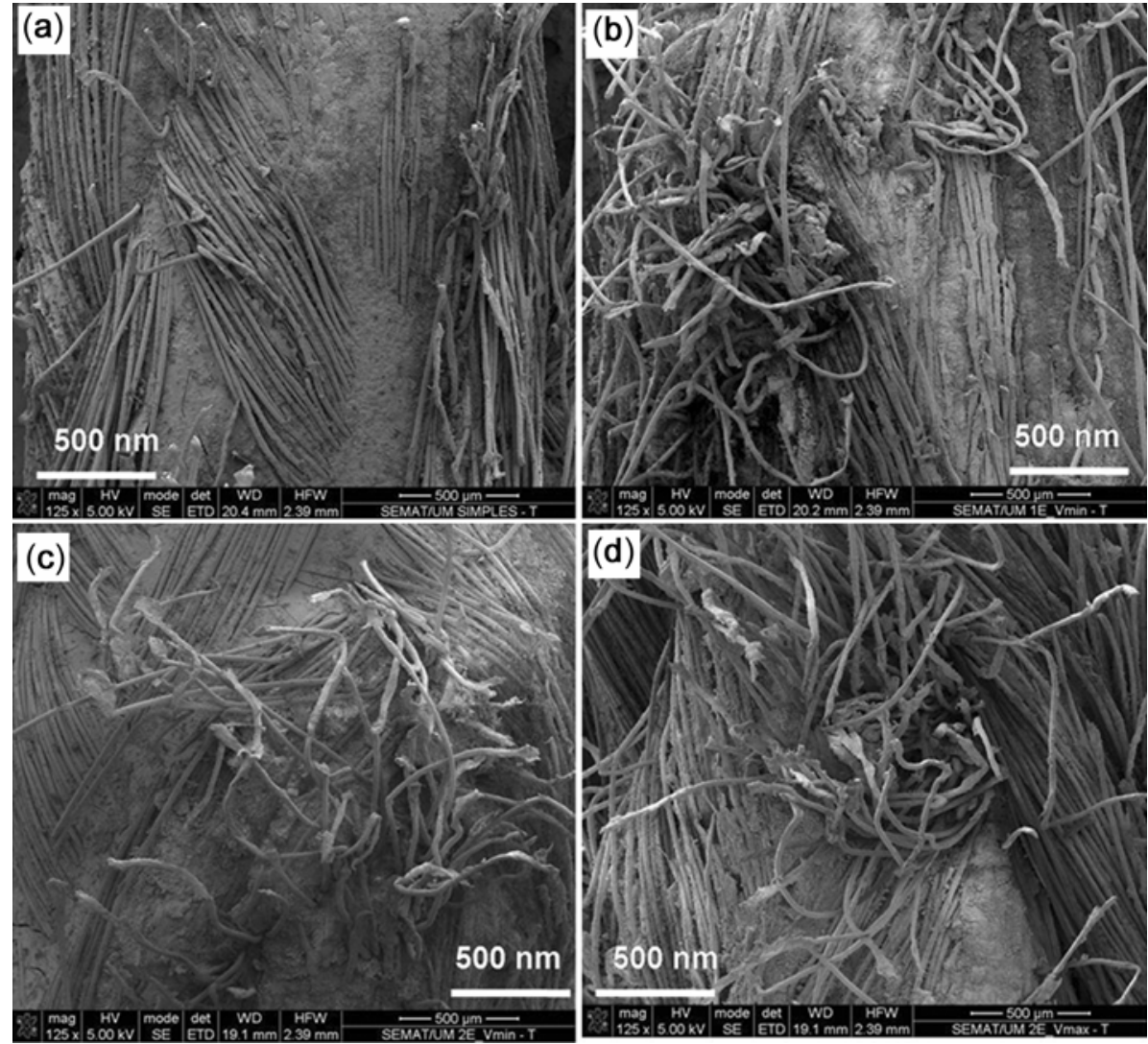

Figure 5. Morphology of pull-out surface of various composite rods: (a) SIMPLE, (b) 1B_LS, (c) 2B_LS and (d) 2B_HS.

case of 2B_LS was comparatively less (figure 5c) due to poor bonding with the mortar and, as a result, the lowest pull-out strength was achieved in this type of rods.

\section{Conclusions}

In the present study, novel surface-tailored composite rods were produced using braiding technique and the bond behaviour of these rods with cement mortar was studied using pull-out tests. The distance between the surface ribs was varied by adjusting the take-up velocity and using one or two braids instead of simple yarns in the braided cover of the rods. It was observed that the surface-tailored rods produced with 2 braids on the surface and using a higher take-up speed $(1.07 \mathrm{~m} / \mathrm{min})$ showed excellent adhesion with the cement mortar and a $134 \%$ higher pull-out force than the simple composite rods without surface ribs. Therefore, these novel composite rods can solve the problem of debonding of FRP rods with cementitious matrix and may prove very effective reinforcing materials of concrete due to full utilization of their tensile strength. Moreover, they can be readily adapted for real applications due to low-cost and simple manufacturing technique.

\section{References}

Baena M, Torres L, Turon A and Barris C 2009 Compos. Part B 40784

Fangueiro R, Gonilho C, Araújo M and Jalali S 2007 Int. Patent PCT/IB2007/054051

Hollaway L C 2010 Constr. Build. Mater. 242419

Iovinella I, Prota A and Mazzotti C 2013 Constr. Build. Mater. 40533

Kalupahana W K K G, Ibell T J and Darby A P 2013 Constr. Build. Mater. 4358

Sayed-Ahmed E Y, Bakay R and Shrive N G 2009 Electron. J. Struct. Eng. 945

Sharakya I A, Torres L, Baena M and Miàs C 2013 Compos. Struct. 99350 